\title{
QANE AFI

\section{Baccalaureate Program Evaluation, Preceptors, And Closing The Theory-Practice Gap: Is There A Connection?}

Catherine Ann Thibeault

Trent University, cthibeault@trentu.ca

Follow this and additional works at: https://qane-afi.casn.ca/journal

Part of the Nursing Commons

\section{Recommended Citation}

Thibeault, Catherine Ann (2017) "Baccalaureate Program Evaluation, Preceptors, And Closing The Theory-Practice Gap: Is There A Connection?," Quality Advancement in Nursing Education - Avancées en formation infirmière: Vol. 3: Iss. 1, Article 6.

DOI: https://doi.org/10.17483/2368-6669.1088

This Article is brought to you for free and open access by Quality Advancement in Nursing Education - Avancées en formation infirmière. It has been accepted for inclusion in Quality Advancement in Nursing Education - Avancées en formation infirmière by an authorized editor of Quality Advancement in Nursing Education - Avancées en formation infirmière. 


\section{Baccalaureate Program Evaluation, Preceptors, And Closing The Theory-Practice}

Gap: Is There A Connection?

\section{Cover Page Footnote}

I gratefully acknowledge Leslie Grightmire, RN, EdD, whose work contributed to the development of this article. Note de la page couverture Je remercie Leslie Grightmire, inf., D. Éd., dont le travail a contribué à la conception de cet article. 
Two central questions guide the development of baccalaureate nursing curricula: "What will program graduates need to know?" and "How can we be sure that students are learning what they need to learn?" In order to ensure that graduates are prepared to practice according to the standards of the profession, nursing faculty invest significant time and effort in program evaluation. Program evaluation most commonly includes an evaluation of program purpose, implementation processes, structure, and outcomes. In Canada, the Canadian Association of Schools of Nursing (CASN) requires that schools meet accreditation standards in part by having an evaluation plan that "guides the assessment of curriculum, program delivery, and program outcomes" (CASN, 2014, p. 28).

Nursing faculty consider stakeholder feedback to be a critical element of program evaluation, in part to ensure that curricula remain relevant to professional nursing practice and to ensure the program outcomes appropriately match the needs of the health care system, nursing service users, and the nursing profession. It is common practice to consult with program stakeholders for feedback related to achievement of program outcomes. Evaluators ask questions such as "Are Program X graduates able to practice within a reasonable amount of time after a period of orientation?" or "How do you rate your level of satisfaction with graduates of Program X?" In undergraduate health professional education, evolving workplace expectations may conflict with knowledge development in the relevant discipline (Coyle, 2011), and it has been reported that many students of nursing see a wide gap between what they learn in the classroom and what they do in clinical practice (Benner, Sutphen, Leonard, \& Day, 2009). Nursing is both a knowledge enterprise and a practice profession; pre-licensure education programs must help students bridge any gaps (perceived or real) between disciplinary knowledge and practice knowledge. In this article, I reflect on a stakeholder consultation activity carried out by my own nursing program and consider this question: Do conventional stakeholder consultation strategies in pre-licensure nursing programs help educators understand how to minimize the gap between nursing theory and nursing practice? I will propose that they may not, and I will suggest a way forward.

\section{Background}

I began to speculate that there may be a relationship between program evaluation models and a theory-practice gap after I collaborated on a stakeholder consultation project at my school of nursing. As part of this activity, cover letters and surveys were mailed to a subset of fourthyear preceptors. Participants answered questions related to their understanding of the $\mathrm{BScN}$ curriculum, the preceptor role, program learners, and graduates. Approximately $25 \%$ of the surveys were returned. Survey items such as "The BScN curriculum is relevant to clinical nursing practice", "I am familiar with elements of the program", and "I am satisfied with the amount of contact I have with the School and faculty" yielded a median score of 3, or "mostly agree". In addition to completing the survey, participants wrote comments about student and graduate knowledge and skills, learning gaps, quality of clinical experience, readiness and preparation, challenges with preceptor role and recognition, and curriculum content. While the survey suggested that the school of nursing was doing many things right in its relationship with preceptors, there were some very telling comments. For example, one respondent suggested that students needed more psychological preparation in order to minimize moral distress as new graduates; another emphasized the importance of robust knowledge in mental health for all new nurses. Although there were many positive comments about the knowledge, skill, and enthusiasm of the students, participants also commented on the need for more familiarity with the 
curriculum. In general, respondents expressed strong values related to the practice of nursing that needed to be understood by faculty: the importance of basic nursing skills as a foundation for care, the significance of excellent communication, and the need for the novice nurse to be grounded and resilient.

These comments were tantalizing. If such rich information could be uncovered in a brief survey, what more could we learn about nursing practice and nursing education from these RN preceptors? As an educator, scholar, and part of a group of nursing professors with extensive knowledge of the discipline of nursing, I have participated in many curriculum development and evaluation projects. Was it possible that we have been missing something? When it comes to understanding what and how to teach students about the complex world of nursing practice, is it enough to ask for periodic input from stakeholders? Barker and Pittman (2010) recommend that preceptors and faculty establish an "open dialogue" for the purposes of generating support and bridging the theory-practice gap (p. 144). Perhaps preceptors, skilled and knowledgeable nurses, and nurse educators should be more actively and consistently engaged in program evaluation. Further, if there are areas in which theory and practice diverge, would such active participation lead to a resolution of these gaps? How could we achieve this aim?

\section{Preceptors: Key players in nursing education}

There is little question that students of nursing need to engage in clinical practice in order to become expert nurses (Benner, Tanner, \& Chesla, 2009). Students need to perceive coherence between the components of their education that are theory-based and those that are practicebased (Hatlevik, 2012). Partly in recognition of the value that practice-based, preceptor-led experiences offer students and partly as a response to budget constraints and faculty shortages in university programs, it has become more and more likely that student clinical experiences will take place under the guidance of a preceptor (Omansky, 2010). Academic nurses need to foster engagement with nurses in clinical practice (Zawaduk, Healey-Ogden, Farrell, Lyall, \& Taylor, 2014); one of the ways that this can be accomplished is by recognizing preceptor knowledge and clinical expertise (Happell, 2004; Blum, 2009; Barker \& Pittman, 2010).

Preceptors-expert nurses who practice in clinical patient care programs and engage in a one-to-one teaching relationship with pre-licensure nursing students-play a critical role in "ensuring optimal learning" (McClure \& Black, 2013, p. 336). Macwilliams (2010) describe the work of the clinical preceptor as the person who helps the student move from knowing about nursing to knowing how to nurse; Zawaduk and colleagues (2014) assert that preceptorship has been a "key proven strategy in preparing nursing students for safe and competent practice" ( $p$. 215). Given that preceptors play such a key role in education for practice, it is important to ask how academic nurses can capitalize on their unique attributes as practitioners and educators. Situated between practice and education, preceptors are indeed a special group of stakeholders: their perspectives on $\mathrm{BScN}$ curriculum and associated outcomes are unique. It makes sense then that preceptors be actively engaged as partners in nursing program development and evaluation.

\section{Program evaluation models: not all are created equal}

Stakeholder participation in program evaluation is an old idea, but it can look very different depending on the evaluation model used. For example, in proposing a responsive evaluation model, Stake (1983) emphasizes the importance of transactional knowing, that is, considering what the program looks like from the point of view of different participants. Stake proposes that the evaluation process should respond to current problems and identify values that 
need to be protected. Guba and Lincoln (1989) state that all stakeholders, internal and external, have a legitimate interest in the process of program evaluation and proposed that evaluation is a process of negotiation (Abma, 2000). Guba and Lincoln's (1989) model is multi-voiced, interactive, and naturalistic; the design of the evaluation emerges from the claims of stakeholders. Stakeholders and evaluators "present and respond to each other's experiences and interpretation" (Abma, 2000, p. 200). Their responsive-constructivist framework of program evaluation places stakeholders in the role of active designers and participants in the evaluation process. Interaction with stakeholders is hermeneutic and dialectic, and experience is considered to be more important that measurement (Abma, 2000). In fact, the main purpose of program evaluation may be to form a connection with stakeholders that allows for mutual exploration of issues, so that impasses, constructive dialogue, and innovation can result. In a similar vein, Hall, Ahn, and Greene (2012) argue for values-engaged evaluation in which "the perspectives, concerns, and values of all legitimate stakeholders" (p. 198) are highlighted. Evaluation models differ in that stakeholders may be viewed as providers of data, as engaged and interested partners in ongoing consultation, or as full collaborators in the process. The question is not whether stakeholders should be involved in program evaluation, but how their involvement shapes assumptions and values underlying the evaluation process.

Many program evaluation frameworks represent a behaviourist philosophy in which outcome evaluation is privileged. Although Canadian schools are not required to base their evaluations on a specific evaluation theory, and Sauter (2000) reports that most U.S.-based nursing programs do not, conventional evaluation places a great deal of emphasis on evaluation of program outcomes (Greene, 1994). When outcome evaluation takes priority, areas of dissent may become blurred and areas of congruence may be emphasized (Abma, 2000). Program evaluation processes may be politicized in that the evaluation may be structured to serve specific interests (House \& Mathison, 2005). A philosophy of pluralism would allow for consideration of many different realities, and these differences could create rich opportunities for understanding the program being reviewed. Goertzen (2010) considers the metaparadigm of dialectical pluralism to be a helpful way of conceptualizing pluralism. A dialectical pluralist stance recognizes that knowledge is contingent on context and that different points of view interact with each other in a complex way. Rather than living with ongoing parallel realities, dialectical pluralism allows for the recognition of competing views so that possible resolutions can be uncovered (Goertzen, 2010). The sustained tension of the dialectic means that competing theories and perspectives can be combined into "a new workable whole" (Burke Johnson, 2012, p. 752).

At my school, the program evaluation strategy is based on the context, input, process, and product (CIPP) model for evaluation (Stufflebeam, 2003). The CIPP model is considered a comprehensive framework for evaluation, determining what needs to be done and how it should be done (Alkin, 2004). It is a primarily an objectivist model, essentially asking whether or not the program is succeeding; its underlying assumption is that it is possible to reach one correct conclusion. The CIPP model includes opportunities for stakeholders to give feedback (Stufflebeam, 2003) in order to "affirm foundational values", "clarify evaluative criteria", and "contribute needed evaluation" (p. 12). The model assumes that stakeholders and program faculty agree on program values and desired outcomes. Stufflebeam's model includes processes to evaluate goals and measure outcomes. Retroactive evaluation using the CIPP model aids in program accountability. This is particularly useful in nursing education programs, which must undergo periodic approval and accreditation. 
Accrediting bodies do not impose requirements for theory driven evaluation, but their evaluations standards reinforce the behaviourist approach (Handwerker, 2012). A key element of the CASN standard related to "ongoing comprehensive evaluation" (CASN, 2014, p. 38) calls for the assessment of program outcomes. Evaluation models that conform to objectivist or even postpositivist ideals privilege neutrality, and constructivist approaches privilege "particularity and insider perspectives on knowing" (Hall, Ahn, \& Green, 2012, p. 196). Perhaps it makes sense to encourage the adoption of a pluralist framework in which a dialectical process uncovers the disparities and connections between points of view about nursing knowledge, nursing practice, and the nursing program. Given the significance of the data supplied by preceptors in our own program evaluation activity and preceptors' unique knowledge of nursing practice and education, I propose that we move toward a more pluralist ontology in baccalaureate nursing program evaluation, particularly in relation to stakeholder participation. In the same way that nursing faculty establish partnerships with preceptors for clinical teaching, faculty could establish partnerships for program evaluation. In these partnerships, nursing faculty and clinical preceptors could create formal opportunities for ongoing dialogue about clinical practice and nursing education. These dialogues would privilege experience rather than measurement and program activities rather than program intentions.

\section{Program evaluation, preceptors, and the theory-practice gap}

When it comes to deciding what nursing students will be taught, education seems to hold most of the power (Duffy \& Scott, 1998), even though many nursing faculty struggle to maintain clinical currency (Rochester, Waters, Rogan, \& Wylie, 2006). Scheller (2008) reports that only $52 \%$ of nurse academics in Illinois believed that academics should have clinical nursing practice as part of their academic role. Rochester and colleagues (2006) state that even though the university has formal responsibility for nursing education, they have no formal role in clinical practice. Despite this, nursing faculty make most of the decisions about program evaluation frameworks and stakeholder involvement in evaluation.

How might the adoption of a pluralist stance in program evaluation affect the theorypractice gap in nursing and nursing education? It is unlikely that the theory-practice gap, where it exists, or the factors that contribute to the gap, perceived or real, will ever be completely resolved. In fact, it may be prudent to question the received notion that the theory-practice gap is negative (Sellman, 2010). Because of their unique situation as clinicians and teachers, preceptors will raise concerns and identify issues that may not have been visible to nursing faculty or that nursing faculty dismiss. For example, in our preceptor survey, preceptors wrote that students were not getting enough clinical time before a senior consolidation experience, that all students should receive clinical practice in mental health nursing as part of their program, and that students should be more prepared for the moral distress that they experience when they cannot practice the way they were taught. Most nursing faculty would have received similar feedback from nurses in clinical practice; perhaps some changes would have been instituted. It is also possible that some nursing faculty would label these concerns as naive or uninformed. The point is that nursing faculty retain the power; they can choose to act or not act. The active engagement of preceptors in designing and participating in program evaluation may initially serve to expose more areas of difference than were previously understood. However, a pluralist stance exposes aspects of the gap and creates opportunities for ongoing and authentic interaction. In this way, practicing nurses and educators may be tempted to abandon their most extreme positions and move toward a "radical middle" ground (Pearson, 1996). Active engagement of preceptors in 
program evaluation could be a major component of a committed and collaborative relationship, with the aim of promoting coherence between theory and practice and the development of a truly responsive curriculum.

Even if a program evaluation process commits to a particular values perspective, such as pluralistic inclusivity of multiple voices and democratic decision-making, there may still be a need to make decisions about specific aspects of a program, including achievement of program outcomes. Participatory methods may create opportunities for the stakeholders to frame the evaluation but still respect the requirements of the program being evaluated (Rodrigues-Campos, 2012). For example, nursing faculty could work with a large group of preceptors in evaluation and program planning, jointly developing evaluation strategies and program outcomes. The central question of the evaluation process might be "How do program members and program stakeholders experience the program? What is its meaning?" Members and stakeholders reflect on the assumptions that guide their work, and they identify and attempt to inhabit other possible perspectives (Koch, 1998). As parties carefully listen to each other and define the shared problem, the resulting dialogue can uncover previously overlooked, salient experiences. In this approach, impasses are understood to be opportunities for breakthroughs and innovation (Abma, 2000). The most important factor in program evaluation is the way activities are carried out, rather than the activities themselves (Rodrigues-Campos, 2012). Evaluation of program outcomes can form one component of an evaluation framework as long as there is an active and ongoing communication between the parties involved, and an active exchange of ideas and methods.

\section{Conclusion}

After an experience with preceptor feedback in a program evaluation activity based on the CIPP model (Stufflebeam, 2003), I conclude that preceptor knowledge of nursing practice and baccalaureate nursing curricula is a significant resource for nursing faculty who are working to evaluate, develop, and improve pre-licensure nursing education. The mandate to prepare graduates to practice according to the high standards of the profession and the risk of theorypractice gap creates an impetus for discussion and dialogue between educators and clinicians. Preceptors seek to understand the educational preparation of the students with whom they work. Preceptor-stakeholders should do more than contribute data to program evaluation; they should be embraced as partners in the evaluation process. The work of evaluation would then become a dialectical engagement to explore meaning and identify shared values, as declared in program activities and outcomes. Rather than relying on rigid objectivist measures, this kind of evaluation process would embrace the political, seek to uncover and expose bias, and search for meaningful compromise. It is likely that there are many ways to achieve coherence between theoretical and practice teaching, but an active and engaged dialogue between nursing faculty and preceptorstakeholders in an evaluation process may be one of the most productive and practical.

At present, this point of view is highly speculative. Furthermore, the demands of academic teaching and clinical practice create barriers for individual participation in an ongoing collaboration. Those who employ nurses in practice may hesitate to release them from their clinical practice work in order to spend time working with faculty in evaluation activities. Some nursing faculty may hesitate to share decision-making in matters of curriculum with their nursing practice peers. However, both nursing faculty and nurses in clinical practice would surely find worth in a program evaluation process that helps them to better understand the complexities of 
Quality Advancement in Nursing Education - Avancées en formation infirmière, Vol. 3, Iss. 1 [2017], Art. 6

nursing and nursing education and engage in educational endeavours that are responsive to the needs of nurses, patients, and the health care system in general. 


\section{References}

Abma, T. (2000). Stakeholder conflict: A case study. Evaluation and Program Planning, 23, 199-210. doi:10.1016/S0149-7189(00)00006-9

Alkin, M. (2004). Evaluation roots: Tracing theorists' views and influences. Thousand Oaks, CA: Sage.

Barker. E., \& Pitman, O. (2010). Becoming a super preceptor: A practical guide to preceptorship in today's clinical climate. Journal of the American Academy of Nurse Practitioners, 27, 144-149. doi:10.1111/j.1745-7599.2009.00487.x

Benner, P., Tanner, C., \& Chesla, C. (2009). Expertise in nursing practice: Caring, clinical judgment and ethics. New York, NY: Springer.

Benner, P., Sutphen, M., Leonard, V., \& Day, L. (2010). Educating nurses. A call for radical transformation. San Francisco, CA: Jossey-Bass.

Blum, C. (2009). Development of a clinical preceptor model. Nurse Educator, 34(1), 29-33. doi:10.1097/01.NNE.0000343394.73329.1d

Burke Johnson, R. (2012). Editorial. Dialectical pluralism and mixed research. American Behavioral Scientist, 56(6), 751-754. doi:10.1177/0002764212442494

Canadian Association of Schools of Nursing (2014). CASN accreditation program standards. Ottawa, ON: Author.

Coyle, J. (2011). Strategies for evaluating undergraduate degree programs. Collected Essays on Teaching and Learning: Creative Teaching and Learning: Exploring. Shaping. Knowing. 4, 25-30. Retrieved from http://celt.uwindsor.ca/ojs/leddy/index.php/CELT/issue/viewIssue/369/1

Duffy, K., \& Scott, P. (1998). viewing an old issue through a new lens: A critical theory insight into the education-practice gap. Nurse Education Today, 18, 183-189.

doi:http://dx.doi.org/10.1016/S0260-6917(98)80077-4

Goertzen, J. (2010). Dialectical pluralism: A theoretical conceptualization of pluralism in psychology. New Ideas in Psychology, 28, 201-209. doi:10.1016.j.newideapsych.2009.09.013.

Greene, J. (1994). Qualitative program evaluation: Practice and promise. In N. K. Denzin \& Y. S. Lincoln (Eds.), Handbook of qualitative research (pp. 530-544). Thousand Oaks, CA: Sage Publications

Guba, E., \& Lincoln, Y. (1989). Competing paradigms in qualitative research. In N. Denzin \&Y. Lincoln (Eds.), Handbook of qualitative research (pp. 105-117).Thousand Oaks, CA: Sage.

Hall, J., Ahn, J., \& Greene, J. (2012). Values engagement in evaluation: Ideas, illustrations, and implications. American Journal of Evaluation, 33, 195-207. doi:10.1177/1098214011422592

Handwerker, S. (2012). Transforming nursing education: a review of current curricular practices in relation to Benner's latest work. International Journal of Nursing Education Scholarship, 9(1), (Online) 1548-923X. doi:10.1515/1548-923X.2510 
Happell, B. (2004). A model of preceptorship in nursing: Reflecting the complex functions of the role. Nursing Education Perspectives, 30(6), 372-376. Retrieved from http://journals.lww.com/neponline/toc/2009/11000

Hatlevik, I. (2012). The theory-practice relationship: Reflective skills and theoretical knowledge as key factors in bridging the gap between theory and practice in initial nursing education. Journal of Advanced Nursing, 68(4), 868-877. doi:10.1111/j.13652648.2011.05789.x

House, E., \& Mathison, S. (2005). Methodology and values in evaluation. (Online version). Educational Theory, 34, 151-152. doi:10.1111/j.1741-5446.1984.00151.x (Original version, 1984).

Koch, T. (1998). Reconceptualizing rigour: The case for reflexivity. Journal of Advanced Nursing, 28(4), 882-890. doi:10.1046/j.1365-2648.1998.00725.x

Macwilliams, B. R. (2010). Through the eyes of the clinical preceptor: A grounded theory. Abstract. Retrieved from http://gradworks.umi.com/34/34/3434286.html

McClure, E., \& Black, L. (2013). The role of the clinical preceptor: An integrative literature review. Journal of Nursing Education, 52(6), 335-341. doi:10.3928/01484834-2013043002

Omansky, G. (2010). Staff nurses' experiences as preceptors and mentors: an integrative review. Journal of Nursing Management, 18, 697-703. doi:10.1111/j.1365-2834.2010.01145.x.

Rochester, S., Waters, C., Rogan, F., \& Wylie, A. (2006). The nurse academic in the clinical learning setting: An evolving partnership role. Contemporary Nurse, 23(1), 12-20. doi:http://dx.doi.org/10.5172/conu.2006.23.1.12

Rodrigues-Campos, L. (2012). Advances in collaborative evaluation. Evaluation and Program Planning, 35(4), 523-528. doi:10.1016/j.evalprogplan.2011.12.006

Sauter, M. (2000). Exploration of program evaluation in baccalaureate nursing education (Doctoral dissertation). Retrieved from CINAHL, EBSCOhost (Accession: 109875664).

Scheller, J. (2008). Clinical competency levels of practicing and non-practicing AD nurses faculty in Illinois. (Doctoral dissertation). Retrieved from CINAHL, EBSCOhost (Accession: 109851826)

Sellman, D. (2010). Mind the gap: philosophy, theory and practice. Nursing Philosophy, 11, 8587. doi:10.1111/j.1466-769X.2010.00438.x

Stake, R. (1983). Program evaluation, particularly responsive evaluation. In G. Madaus, M. Scriven, \& D. Stufflebeam (Eds.) Evaluation models: Viewpoints on education and human service models of evaluation (pp. 343-362). Boston, MA: Kluwer-Nijhoff Publishing.

Stufflebeam, D. (2003). The CIPP model for evaluation. In T. Kellaghan and D. Stufflebeam (Eds.). The international handbook of educational evaluation (pp. 31-62). Boston. MA: Klewer. 
Zawaduk, C., Healey-Ogden, M., Farrell, S., Lyall, C., \& Taylor, M. (2014). Educator informed practice within a triadic preceptorship model. Nurse Education in Practice, 14, 214-219. doi:http://dx.doi.org/10.1016/j.nepr.2013.08.008 